\title{
Continuation or termination of metformin in diabetic patients exposed to iodinated contrast medium?
}

\author{
Mohamad Ali Dayani* ${ }^{(\mathbb{D}}$ \\ Department of Radiology, Shahrekord University of Medical Sciences, Shahrekord, Iran
}

\section{ART I C L E I N F O}

Article Type:

Review

\section{Article History:}

Received: 10 April 2019

Accepted: 7 June 2019

Published online: 29 June 2019

\section{Keywords:}

Iodinated contrast media,

Lactic acidosis, Metformin,

Chronic kidney disease,

Metformin-associated lactic

acidosis, Hypoxemia

\begin{abstract}
A B S T R A C T
Lactic acidosis (LA) secondary to metformin administration is a rare incident with a very high mortality rate $(\geq 50 \%)$. Hypoxia has been suggested to contribute to metformin-associated lactic acidosis (MALA) in 90\% of patients developing this condition. In susceptible patients such as those with renal insufficiency, the level of plasma metformin is increased particularly after exposure to iodinated contrast media (ICM). One major concern in patients with renal insufficiency is to adjust the metformin dose based on the renal functional capacity prior to ICM examination. In this review, we assessed metformin tolerable threshold in diabetic patients with renal failure. We also reviewed metformin withdrawal criteria in patients with chronic kidney disease (CKD) exposed to intravenous ICM during angiography. Our results indicated that in patients with insufficient renal function (i.e. $30<$ estimated glomerular filtration rate (eGFR) $<60$ and $30<\mathrm{eGFR}<45 \mathrm{~mL} / \mathrm{min} / 1.73 \mathrm{~m}^{2}$ ), or those with acceptable renal function (eGFR $\geq 60 \mathrm{~mL} /$ $\min / 1.73 \mathrm{~m}^{2}$ ) and concomitant comorbidities, the decision to withhold or reinitiate metformin should be based on patient's medical condition.
\end{abstract}

Implication for health policy/practice/research/medical education:

It has been recommended that in patients with compromised renal function (i.e. $30<\mathrm{eGFR}<60$ and $30<\mathrm{eGFR}<45 \mathrm{~mL} / \mathrm{min} / 1.73$ $\mathrm{m}^{2}$ ) and those with normal renal function and other co-morbidities, either withholding or continuing of metformin prior to iodinated contrast medium exposure should be based on patient's medical condition.

Please cite this paper as: Dayani MA. Continuation or termination of metformin in diabetic patients exposed to iodinated contrast medium? J Renal Inj Prev. 2019;8(3):185-189. DOI: 10.15171/jrip.2019.34.

\section{Introduction}

Lactic acidosis (LA) is a marker of inadequate tissue perfusion and oxygen supply. Insufficient oxygen delivery triggers anaerobic metabolism which finally transforms pyruvate to lactate (1). Metformin-associated lactic acidosis (MALA) is a relatively rare incident; however, the condition renders a very high mortality rate (2). Evidences from comprehensive meta-analyses and clinical studies have specified the efficiency and safety of metformin in appropriate dose. On the other hand, even elevated serum concentration of metformin alone is rarely indicated as a trigger for LA. Actually, in more than $90 \%$ of patients with MALA, the condition has been associated with a hypoxic circumstance that can prompt LA $(3,4)$. MALA is generally preventable in most outpatient individuals. In fact, dose adjustment strategies can be effectively implemented to avoid MALA in patients with kidney failure, hepatic insufficiency, severe hypoxia, chronic heart failure, shock (e.g. surgery) and those who abused alcohol (5). Nevertheless, in vulnerable individuals with predisposing conditions (i.e. metformin overdose, lactate level $>5 \mathrm{mM}$ or large anion gap), severe academia (blood $\mathrm{pH}<7.4$ ), and low serum bicarbonate level $(<22 \mathrm{mM}))$, MALA may be triggered following metformin accumulation in the body (6).

The accumulation of metformin alone can explain the development of LA in only $\leq 10 \%$ of cases who mostly are also identified with either metformin overdose or acute kidney injury. The MALA is considered as the LA developed following metformin administration in patients with no obvious other predisposing and related diseases (7).

Hypoxia is a serious predisposing factor and a prognostic indicator for MALA. Diabetes and diabetic nephropathy (8), renal failure $(9,10)$, and intravascular iodinated contrast media (ICM) (11) decrease medullary 
oxygenation predisposing medullary region to hypoxia. Actually, the intensity of hypoxia; and not the lactate or metformin concentrations, predicts the mortality rate in patients, and therefore metformin administration must be reconsidered in the presence of tissue hypoxia (12). Although a recent study has clarified no association between metformin administration and LA; however, this indication may not be applicable to susceptible individuals with metformin overdose (13).

Reduced kidney function and metformin clearance are the most significant risk factors of MALA. In this regard, diabetic patients are at risk of LA following metformin administration. Other risk factors of MALA include reduced tissue oxygenation (such as in heart failure, hypoxemia, ICM exposure, sepsis and shock), as well as disturbed lactate metabolism (such as in alcoholism, or liver fibrosis) (Table 1) (5). Therefore, it is highly recommended to avoid metformin administration in these contraindicated conditions.

\section{Materials and Methods}

For this review, we used a variety of sources including PubMed, Web of Science, Embase, EBSCO, Google Scholar and Scopus. The search was conducted, using combinations of the following key words and or their equivalents; iodinated contrast media, lactic acidosis, metformin, chronic kidney disease, metforminassociated lactic acidosis, hypoxemia, acute kidney injury, contrast induced nephropathy, percutaneous coronary intervention, nephrotoxicity and glomerular filtration rate.

\section{Contrast induced nephropathy}

Radiology imaging techniques such as angiography and computed tomography angiography (CT-angiography) usually provide evidence about the structure of blood vessels and body organs assisting in the diagnosis and treatment of various diseases. In most of these techniques, ICMs which are renal toxic agents and may cause complications in patients with renal disease are administered. In patients with pre-existing renal damage, particularly diabetic individuals, using ICMs in radiographic procedures may lead to contrast-induced nephropathy (CIN). CIN is defined as the elevation of

Table 1. Risk factors of metformin-associated lactic acidosis

\begin{tabular}{ll}
\hline Risk factors & Examples \\
\hline $\begin{array}{l}\text { Reduced metformin } \\
\text { clearance }\end{array}$ & $\begin{array}{l}\text { Acute kidney injury } \\
\text { Chronic kidney disease }\end{array}$ \\
$\begin{array}{l}\text { Sepsis, shock (e.g. surgery), } \\
\text { hypovolemia, heart failure, ICM } \\
\text { exposure }\end{array}$ \\
$\begin{array}{l}\text { Dysregulated lactate } \\
\text { metabolism }\end{array}$ & Alcohol abuse, liver fibrosis \\
\hline
\end{tabular}

serum creatinine $\geq 25 \%$ of the standard level within 48 hours. ICMs may promote their nephrotoxic effects either indirectly by induction of renal hypoxia through hemodynamic alterations such as inducing renal vasoconstriction, and reducing vasodilatation, kidney blood supply, blood pressure and glomerular filtration rate or directly by cytotoxic effects against renal tubular and endothelial cells $(11,14)$. As kidneys receive almost $20 \%$ of cardiac output, they are particularly sensitive to hypoxia. Decreased kidney oxygenation, particularly renal medulla hypoxia, is an indicator of CIN. Applying ICM also increases the viscosity of kidney arterioles that are the main sources of renal medulla blood supply, which further exaggerating medullary hypoxia. These agents can also worsen, the endothelial dysfunction by inducing toxic effects toward endothelial and other renal cells (15).

Metformin-associated lactic acidosis following ICM induced nephropathy

By reducing kidney function, ICMs increase the risk of metformin accumulation predisposing to LA. Because of the presumed association between ICM and the risk of LA in patients using metformin, the present recommendations restrict the administration of metformin in patients exposing to such agents, such as those referred for percutaneous coronary intervention (PCI) (16). Nonetheless, the incidence of nephrotoxicity after ICM exposure is very low in individuals with normal serum creatinine level and renal function $(17,18)$. The risk of MALA after ICM exposure is particularly escalated in simultaneous presence of other contraindications of metformin usage, particularly renal insufficiency (19). In accordance, multiple studies on diabetic patients treated with metformin have indicated that the risk of CIN is minimal in diabetic patients without renal disorder $(3,16)$. Overall, metformin avoidance to prevent LA in patients who are subjected to intravenous ICM may be only restricted to those with abnormal renal function.

\section{Metformin administration in patients with chronic} kidney disease

There has been a point of contrary to either administer lowdose metformin in patients with partial renal impairment (20) or withdraw the drug in patients with advanced chronic kidney disease (CKD) $(21,22)$. There have been recommendations to eliminate the renal functional limitations on metformin administration. On the other hand, there have been many cases of severe side effects and unfavorable complications related to metformin (23). In fact, it has been argued that the restricting guidelines have likely saved thousands of lives each year from LA, hypoglycemia, and pancreatitis (6).

The estimated glomerular filtration rate (eGFR) which is reported as $\mathrm{mL} / \mathrm{min} / 1.73 \mathrm{~m}^{2}$ is calculated based on serum creatinine, weight, height, age, and/or gender 
(24). The eGFR has been a better indicator respective to serum creatinine for predicting renal insufficiency. In a cohort study on more than 50.000 patients with type 2 diabetes, the predictability of different eGFRs has been assessed on the safety of metformin administration (25). The study showed, the risk of LA was $\sim 13$-fold higher in patients with reduced renal function treated with $>2 \mathrm{~g} / \mathrm{d}$ metformin in comparison with patients with no history of metformin exposure. The risk of either LA or elevated lactate concentration boosted in patients with severe renal failure $\left(30 \leq \mathrm{eGFR}<60 \mathrm{~mL} / \mathrm{min} / 1.73 \mathrm{~m}^{2}\right)$ with the risk being highly escalated in patients received prolonged metformin therapy.

In patients without renal problems, metformin improves glucose and lipid metabolisms, helps to lose weight, and finally postpones diabetes development. It has been argued that contradicting metformin administration in CKD patients may deprive millions of diabetic patients from the beneficial effects of this therapeutic agent. Clinical practice guidelines have suggested the thresholds of kidney failure and low GFR for protecting CKD patients from potential metformin adverse effects. Drug administration organizations and expert associations in various countries have also suggested metformin cut off limits to be applied in CKD patients.

The National Institute for Health and Clinical Excellence (NICE), American Diabetes Association (ADA), European Association for Study of Diabetes (EASD), Kidney Disease: Improving Global Outcomes (KDIGO), Royal Australian College of General Practitioners (RACGP), Japanese Society of Nephrology (JSN), National Kidney Foundation Kidney Disease Outcomes Quality Initiative (NKF KDOQI) (6), British National Formulary (BNF) and Japanese Society of Nephrology (JSN) have suggested that metformin administration to be reconsidered at eGFR $\leq 45 \mathrm{~mL} / \mathrm{min} / 1.73 \mathrm{~m}^{2}$ and discontinued at eGFR $\leq 30 \mathrm{~mL} /$ $\mathrm{min} / 1.73 \mathrm{~m}^{2}(26)$.

It should be stated that eGFR $\leq 3030 \mathrm{~mL} / \mathrm{min} / 1.73$ $\mathrm{m}^{2}$ has been the definite contraindication of metformin administration in most recommendations. Metformin may be continued at eGFR $\leq 60 \mathrm{~mL} / \mathrm{min} / 1.73 \mathrm{~m}^{2}$; however, renal function must be monitored approximately three times annually in this condition. In patients with eGFR $\leq 45$ $\mathrm{mL} / \mathrm{min}$ per $1.73 \mathrm{~m}^{2}$, metformin dose must be readjusted and decreased almost to half the primary dose, since renal function must be evaluated approximately four times annually (27) (Table 2). Depending on previous medical history and the presence of other co-morbidities such as exposure to nephrotoxic ICM agents, further caution is required on administrating metformin in patients at risk of sudden decline in renal function. Maximum daily metformin doses of 2000 and $1000 \mathrm{mg}$ have been proposed in patients with a eGFR of $45-60 \mathrm{~mL} / \mathrm{min} / 1.73 \mathrm{~m} 2$ and $30-45 \mathrm{~mL} / \mathrm{min} / 1.73 \mathrm{~m}^{2}$ respectively (28).

Metformin administration in patients with renal insufficiency undergoing ICM exposure

The development of MALA; in addition to the exposition to metformin, is modulated by the presence of other risk factors such as renal insufficiency and exposure to ICMs. This fact indicates the necessity for reconsidering metformin administration in patients with renal insufficiency during ICM procedure. Discontinuation of metformin before ICM exposure should be directed based on the risk of LA and baseline kidney function (29). In patients with compromised (i.e. $30<\mathrm{GFR}<60$ $\mathrm{mL} / \mathrm{min} / 1.73 \mathrm{~m}^{2}$ ) or normal kidney function, the drug withdrawal must be decided considering the patients' medical history. Because of the risk of CIN, monitoring serum-creatinine level seems necessary in all patients. While there has been no established relationship between metformin administration and either intravascular ICM exposure or nephrotoxicity, nevertheless, interactions between metformin, ICM and LA may be a hazardous combination leading to renal damage. The risk of metformin accumulation and LA is exaggerated in patients with CIN. The prevalence of CIN has been reported in the range of $0.1 \%$ to $13 \%$ with preexisting renal damage being an independent risk factor for this condition (30). One major point of concern in patients undergoing ICM has been the level of renal function in which metformin should be stopped or restarted. Table 3 presents different guidelines on metformin administration during ICM in diabetic patients.

Based on the statements presented in Tables 2 and 3, the followings can be guidelines concluded;

- Some guidelines (such as ACR, CAR and RANZCR) have not regarded the eGFR $\leq 30 \mathrm{~mL} / \mathrm{min} / 1.73 \mathrm{~m}^{2}$ as an absolute contraindication for metformin discontinuation before ICM exposure and suggested that the drug should be only stopped immediately prior to the exposure (31).

- In patients with CKD, some guidelines have recommended that metformin should be stopped at

Table 2. Suggested instructions for adjusting the dose of metformin based on eGFR

\begin{tabular}{ll}
\hline eGFR $\left(\mathrm{mL} / \mathrm{min} / \mathbf{1 . 7 3} \mathrm{m}^{2}\right)$ & Action required \\
\hline$>60$ & Continue, check renal function annually \\
$45-60$ & Continue and monitor renal function three times per year \\
$30-45$ & Reduced dose to almost half of primary dose, check renal function check four times per year \\
$<30$ & Contraindicated, stop metformin administration \\
\hline
\end{tabular}


Table 3. The guidelines and recommendations on metformin administration during ICM procedure in diabetic patients based eGFR

\begin{tabular}{|c|c|c|c|c|c|}
\hline Recommendations & ACR & CAR & ESUR & RCR & RANZCR \\
\hline $\begin{array}{l}\text { Discontinuing } \\
\text { Metformin (before } \\
\text { iodine contrast } \\
\text { media method) }\end{array}$ & $\begin{array}{l}\text { eGFR } \geq 30 ; \text { no } \\
\text { need/ eGFR<30 } \\
\text { stop at the time } \\
\text { or } 48 \text { hours before } \\
\text { exposure }\end{array}$ & $\begin{array}{l}\text { 1. eGFR<45; at the time } \\
\text { of contrast exposure. } \\
\text { 2. eGFR }<30 \text { or } \mathrm{AKI}: 48 \\
\text { hours before exposure }\end{array}$ & $\begin{array}{l}\text { 1.eGFR } \geq 45 \text { (intravenous): no need } \\
\text { 2. } 30 \leq e G F R<59 \text { (intra-arterial) and } \\
30 \leq e G F R<44 \text { (intravenous): } 48 \\
\text { hours before exposure } \\
\text { 3. eGFR<30 and in case of } \\
\text { other illness: metformin is } \\
\text { contraindicated }\end{array}$ & $\begin{array}{l}\text { eGFR > 60: no need } \\
\text { eGFR<60, } \\
\text { consultation with } \\
\text { the referring } \\
\text { clinician to stop for } \\
48 \text { hours }\end{array}$ & $\begin{array}{l}\text { eGFR } \geq 30: \\
\text { continue } \\
\text { eGFR } \leq 30 \text { stop } \\
\text { metformin at the } \\
\text { time of contrast } \\
\text { exposure }\end{array}$ \\
\hline $\begin{array}{l}\text { Restarting } \\
\text { Metformin (after } \\
\text { iodine contrast } \\
\text { media method) }\end{array}$ & $\begin{array}{l}\text { Withhold for } 48 \\
\text { hours after the } \\
\text { procedure and } \\
\text { restart only after } \\
\text { monitoring renal } \\
\text { function }\end{array}$ & $\begin{array}{l}\text { Withhold for } 48 \text { hours } \\
\text { after the procedure } \\
\text { and restart only after } \\
\text { ensuring stable renal } \\
\text { function }\end{array}$ & $\begin{array}{l}\text { Withhold for } 48 \text { hours after the } \\
\text { procedure and restart only after } \\
\text { ensuring stable renal function }\end{array}$ & $\begin{array}{l}\text { Consultation } \\
\text { with the referring } \\
\text { clinician to stop for } \\
48 \text { hours }\end{array}$ & $\begin{array}{l}\text { Withhold at least } \\
48 \text { hours after } \\
\text { procedure and } \\
\text { restart only after } \\
\text { checking renal } \\
\text { function }\end{array}$ \\
\hline
\end{tabular}

American College of Radiology (ACR), Canadian Association of Radiologists (CAR), European Society of Urogenital Radiology (ESUR), Royal College of Radiologists (RCR), Royal Australian and New Zealand College (RANZC) / eGFR (mL/min/1.73 $\mathrm{m}^{2}$ ).

any eGFR before intravenous ICM administration (6). On the other hand, in patients with compromised renal function (i.e. either $30<\mathrm{eGFR}<60$ or $30<\mathrm{eGFR}<45$ $\mathrm{mL} / \mathrm{min} / 1.73 \mathrm{~m}^{2}$ ) and those with normal kidney function and other co-morbidities, the decision on withholding and reinitiating metformin prior or at the time of exposure should be based on the patient's medical condition (32).

- It appears to be safe to continue metformin in patients with normal renal function (i.e. eGFR $>60$ $\mathrm{mL} / \mathrm{min} / 1.73 \mathrm{~m}^{2}$ ) with no other comorbidities.

- The, g-I/eGFR <1.42 formula is an easy and helpful indicator for establishing the safe iodinated contrast medium-dose based on the exposure eGFR values. Moreover, g-I/eGFR might have a close relationship with the development of nephropathy requiring dialysis as well as contrast-induced nephropathy (33).

- Other techniques such as magnetic resonance imaging, using iso- or low osmolar ICM agents at the minimum effective dose, and finally applying optimal hydration and other strategies to avoid CIN should be considered in at-risk patients. The commonly conventional practice for radiologists is to stop metformin administration 24 to 48 hours before administration of contrast media in individuals with an eGFR of below $60 \mathrm{~mL} / \mathrm{min} / 1.73 \mathrm{~m}^{2}$ and to renew its administration after testing kidney function 48 hours subsequent the radiography (34).

\section{Conclusion}

Metformin is an efficient drug for managing various diseases; however, its prescription in susceptible individuals and contraindicated conditions (specially kidney insufficiency) necessitates routine monitoring. It is not certain in what level of renal function metformin should be stopped or reinitiated in patients undergoing ICM. Different guidelines have recommended metformin administration requirements in CKD patients, particularly those undergoing ICM procedure. It has been recommended that in patients with compromised renal function (i.e. $30<\mathrm{eGFR}<60$ and $30<\mathrm{eGFR}<45 \mathrm{~mL} /$ $\mathrm{min} / 1.73 \mathrm{~m}^{2}$ ) and those with normal renal function and other comorbidities, either withholding or continuing of metformin prior to ICM exposure should be based on patient's medical condition.

Author's contribution

MAD is the single author of the paper.

Conflicts of interest

The author declared no competing interests.

\section{Ethical considerations}

Ethical issues including plagiarism, double publication, and redundancy have been completely observed by the author.

\section{Funding/Support}

None.

\section{References}

1. Prakash S, Mehta S. Lactic acidosis in asthma: Report of two cases and review of the literature. Can Respir J. 2002;9:2038.

2. Lalau JD. Lactic acidosis induced by metformin: incidence, management and prevention. Drug Saf. 2010;33:727-40. doi: 10.2165/11536790-000000000-00000.

3. Goergen SK, Rumbold G, Compton G, Harris C. Systematic review of current guidelines, and their evidence base, on risk of lactic acidosis after administration of contrast medium for patients receiving metformin. Radiology. 2010;254:261-9. doi: 10.1148/radiol.09090690.

4. Lalau JD, Lacroix C, Compagnon P, de Cagny B, Rigaud JP, Bleichner G, et al. Role of metformin accumulation in metformin associated lactic acidosis. Diabetes Care 1995;18:779-84. doi:10.2337/diacare.18.6.779.

5. Pasquel FJ, Klein R, Adigweme A, Hinedi Z, Coralli R, 
Pimente JL, Umpierrez GE. Metformin-associated lactic acidosis. Am J Med Sci. 2015;349:263-7. doi: 10.1097/ MAJ.0b013e3182a562b7.

6. Kalantar-Zadeh K, Kovesdy CP. Should restrictions be relaxed for metformin use in chronic kidney disease? No, we should never again compromise safety! Diabetes Care. 2016;39:1281-6. doi: 10.2337/dc15-2327.

7. Ortiz-Lasa M, Gonzalez-Castro A, Peñasco Martín Y. Lactic acidosis associated (or induced by) metformin. Med Clin (Barc). 20179;149:415-6. doi: 10.1016/j.medcli.2017.07.009.

8. Heyman SN, Rosenberger C, Rosen S, Khamaisi M. Why is diabetes mellitus a risk factor for contrast-induced nephropathy. Biomed Res Int. 2013;2013: 123589. doi: $10.1155 / 2013 / 123589$

9. Haase VH. Mechanisms of hypoxia responses in renal tissue. J Am Soc Nephrol. 2013;24:537-41. doi: 10.1681/ ASN.2012080855.

10. Takiyama Y, Haneda M. Hypoxia in diabetic kidneys. Biomed Res Int 2014:2014. doi: 10.1155/2014/837421.

11. Heyman SN1, Rosen S, Rosenberger C. Renal parenchymal hypoxia, hypoxia adaptation, and the pathogenesis of radiocontrast nephropathy. Clin J Am Soc Nephrol. 2008;3:288-96.

12. Jones GC, Contraindications to the use of metformin. BMJ. 2003;326: 4-5.

13. Salpeter S1, Greyber E, Pasternak G, Salpeter E. Risk of fatal and nonfatal lactic acidosis with metformin use in type 2 diabetes mellitus. Cochrane Database Syst Rev. 2002:CD002967. doi:10.1002/14651858.CD002967

14. Mamoulakis C, Tsarouhas K, Fragkiadoulaki I, Heretis I, Wilks MF, Spandidos DA, Tsitsimpikou C, Tsatsakis A. Contrast-induced nephropathy: Basic concepts, pathophysiological implications and prevention strategies. Pharmacol Ther. 2017;180:99-112. doi: 10.1016/j. pharmthera.2017.06.009.

15. Fähling M, Seeliger E, Patzak A, Persson PB.Understanding and preventing contrast-induced acute kidney injury. Nat Rev Nephrol. 2017;13:169-80. doi: 10.1038/ nrneph.2016.196.

16. Zeller M, Labalette-Bart M, Juliard JM, Potier L, Feldman LJ, Steg PG, Cottin Y, Roussel R. Metformin and contrastinduced acute kidney injury in diabetic patients treated with primary percutaneous coronary intervention for ST segment elevation myocardial infarction: A multicenter study. Int J Cardiol. 2016;220:137-42. doi: 10.1016/j. ijcard.2016.06.076.

17. Kruse JA. Review: Metformin does not increase risk for lactic acidosis in type 2 diabetes. ACP J Club. 2004;141:7.

18. Sirtori CR, Pasik C Re-evaluation of biguanide, metformin: mechanism of action and tolerability. Pharmacol Res. 1994;30:187-228.

19. Thomsen HS1, Morcos SK. Contrast media and metformin: guidelines to diminish the risk of lactic acidosis in noninsulin-dependent diabetics after administration of contrast media. Eur Radiol. 1999; 9:738-40.

20. DeFronzo R, Fleming GA, Chen K, Bicsak TA. Metformin- associated lactic acidosis: Current perspectives on causes and risk. Metabolism. 2016;65:20-9. doi: 10.1016/j. metabol.2015.10.014.

21. Hung SC, Chang YK, Liu JS, Kuo KL, Chen YH, Hsu CC, et al. Metformin use and mortality in patients with advanced chronic kidney disease: national, retrospective, observational, cohort study. Lancet Diabetes Endocrinol. 2015;3:605-14. doi: 10.1016/S2213-8587(15)00123-0.

22. Kalantar-Zadeh K, Rhee CM. Metformin in chronic kidney disease: more harm than help? Lancet Diabetes Endocrinol. 2015;3:579-81. doi: 10.1016/S2213-8587(15)00133-3.

23. Kalantar-Zadeh K, Uppot RN, Lewandrowski KB. Case records of the Massachusetts General Hospital. Case 232013. A 54-year-old woman with abdominal pain, vomiting, and confusion. N Engl J Med 2013; 369:374-82.

24. Nyman U, Almén T, Aspelin P, Hellström M, Kristiansson M, Sterner G. Contrast-medium-induced nephropathy correlated to the ratio between dose in gram iodine and estimated GFR in ml/min. Acta Radiol. 2005;46:830-42.

25. Ekström N, Schiöler L, Svensson AM. Effectiveness and safety of metformin in 51675 patients with type 2 diabetes and different levels of renal function: a cohort study from the Swedish National Diabetes Register. BMJ Open. 2012;2:e01076. doi: 10.1136/bmjopen-2012-001076

26. National Kidney Foundation. KDOQI clinical practice guideline for diabetes and CKD: 2012 update. Am J Kidney Dis. 2012;60:850-86. doi: 10.1053/j.ajkd.2012.07.005.

27. Lipska KJ, Bailey CJ, Inzucchi SE. Use of metformin in the setting of mild-to-moderate renal insufficiency. Diabetes Care. 2011;34:1431-7. doi: 10.2337/dc10-2361.

28. Inzucchi SE, Lipska KJ, Mayo H, Bailey CJ, McGuire DK. Metformin in patients with type 2 diabetes and kidney disease. A systemic review. JAMA. 2014;312:2668-75. doi: 10.1001/jama.2014.15298.

29. Kim SK, Jung J, Jung JH, Kim KY, Baek JH, Hahm JR.The association between use of metformin and change in serum $\mathrm{CO} 2$ level after administration of contrast medium. Clin Radiol. 2016;71:532-6. doi: 10.1016/j.crad.2016.02.007.

30. Chang JB, Olsen ER, Sumpio BE, Prasad K. Textbook of Angiology edited. New York: Springer-Verlag, LLC, 2000.

31. ACR Manual on Contrast Media Version 10.3. ACR Committee on Drugs and Contrast Media; 2017.

32. Ohno I1, Hayashi H, Aonuma K, Horio M, et. al. Guidelines on the Use of Iodinated Contrast Media in Patients With Kidney Disease 2012 - Digest Version - JSN, JRS and JCS Joint Working Group. Clin Exp Nephrol. 2013;17:441-79. doi: $10.1007 /$ s10157-013-0843-3.

33. Yoon HJ1, Hur SH. Determination of safe contrast media dosage to estimated glomerular filtration rate ratios to avoid contrast-induced nephropathy after elective percutaneous coronary intervention. Korean Circ J. 2011;41:265-71. doi: 10.4070/kcj.2011.41.5.265.

34. Baerlocher MO, Asch M, Myers A. Five things to know about metformin and intravenous contrast. CMAJ. 2013;185:E78.

Copyright (C) 2019 The Author(s); Published by Nickan Research Institute. This is an open-access article distributed under the terms of the Creative Commons Attribution License (http://creativecommons.org/licenses/by/4.0), which permits unrestricted use, distribution, and reproduction in any medium, provided the original work is properly cited. 